\title{
ELEMENTOS SUBJETIVOS NOS SISTEMAS CAUSALISTA, FINALISTA E FUNCIONALISTA
}

\author{
The subjective elements in the causalist, finalist and functional theories
}

\section{Fernando de Oliveira Zonta ${ }^{1}$ Vanessa Morais Kiss ${ }^{2}$}

\author{
${ }^{1}$ Pontifícia Universidade Católica de São Paulo - \\ São Paulo (SP). \\ ${ }^{2}$ Universidade de São Paulo - São Paulo (SP)
}

\section{Autor correspondente:}

Fernando de Oliveira Zonta

E-mail: zonta.fernando@gmail.com

\section{Como citar este artigo:}

ZONTA, F. O; KISS, V.M. Elementos subjetivos nos sistemas causalista, finalista e funcionalista. Revista Saber Digital, v. 14, n. 1, p. 8-26, 2021.

\section{RESUMO}

O presente artigo trata dos elementos subjetivos da teoria do delito (dolo e culpa) nos sistemas causalista, finalista e funcionalista tendo como finalidade principal realizar aproximações e distinções sobre os elementos subjetivos, com especial enfoque à culpa consciente e ao dolo eventual nos sistemas em comento. Inicialmente, é realizada uma incursão, sob uma ótica geral, em cada um desses sistemas a fim de melhor compreendê-los. Após, são especificamente tratadas as aproximações e diferenciações entre os elementos subjetivos nos sistemas causalista, finalista e funcionalista. No desenvolvimento da pesquisa foi utilizada a abordagem qualitativa, com o intuito de percorrer cada um dos sistemas com especial enfoque para os elementos subjetivos da teoria do delito. A teoria do delito sofreu uma ruptura estrutural na passagem do modelo causalista para o finalista, especialmente com o deslocamento do elemento subjetivo da culpabilidade, no causalismo, para a tipicidade, no finalismo. Já na passagem do finalismo para o funcionalismo, embora mantido o elemento subjetivo no campo tipicidade, nota-se uma virada teórica ligada à introdução de critérios de política criminal na formulação da teoria do delito. No tocante à diferenciação entre dolo eventual e culpa consciente, o causalismo neoclássico e o finalismo tendem a colocar suas bases de distinção em patamares muito próximos. Já na teoria funcionalista, identifica-se uma pequena alteração nos critérios de distinção entre o dolo eventual e a culpa consciente, em razão da busca por uma conceituação mais condizente com o sistema de tutela dos bens jurídicos.

Palavras-chave: dolo, culpa, causalismo, finalismo, funcionalismo.

\section{ABSTRACT}

This article analyses the subjective elements of the crime (intent and negligence) in the causalist, finalist and functional theories, having as the main purpose make approximations and distinctions with regard to these elements, with a special focus on conscious negligence and the eventual intent. At first, an incursion is carried out, under a general perspective, in each of these theories, for a better understanding of them. Secondly, we will define the approximations and differentiations between the subjective elements in the causalist, finalist and functional theories. A qualitative approach was employed in order to examine each of these systems with special regard to the subjective elements of the theory of crime. The theory of crime underwent a structural disruption in the transition from causalism to finalism, especially due to the replacement of the subjective element from the culpability to the criminal typicality. On the other hand, in the transition from finalism to the functional system, although the subjective element remains in the scope of the criminal typicality, a theoretical turn takes place concerning the incorporation of criminal policy criteria in the theory of crime. With respect to the distinction between intent and negligence, neoclassical causalism and finalism tend to establish such differentiation on similar grounds. As for the functional theory, a small change is noticeable in the criteria addopted for distinguishing intent and negligence, as a result of the increasing concern with the protection of legal interests.

Keywords: intent, negligence, the causalist theory, the finalist theory, the functional theory. 


\section{INTRODUÇÃO}

O presente artigo tem como objetivo analisar os institutos da culpa e do dolo, com especial enfoque à culpa consciente e ao dolo eventual no causalismo, no finalismo e no funcionalismo, demonstrando os pontos críticos de aproximação e distanciamento entre tais concepções.

Para tanto, inicialmente, buscar-se-á aportar um referencial teórico suficiente para uma melhor compreensão dos sistemas causalista, finalista e funcionalista. Em sequência, serão estabelecidas as aproximações e distinções necessárias acerca da interpretação dada ao dolo e à culpa, com destaque ao dolo eventual e à culpa consciente, nos sistemas causalista, finalista e funcionalista.

\section{As premissas dos sistemas causalista, finalista e funcionalista}

Em termos de dogmática penal, podemos destacar três sistemas que trazem aportes relevantes para a teoria do delito, a saber: o causalismo (clássico e neoclássico, também conhecido como neokantismo), o finalismo e o funcionalismo (teleológico e sistêmico). Cada um desses sistemas possui caracteres próprios e remonta a uma visão de compreensão do direito e das ciências humanas.

\subsection{O sistema causalista clássico}

O causalismo surgiu a partir das ideias de Franz Von Lizst, com importantes contribuições de Ernest Beling e Güstav Radbruch, e tem como característica principal o forte apego às ideias cientificistas que preponderavam no século XIX (NUCCI, 2019, capítulo XIV, item 2.1). 
Trata-se, em verdade, de "produto desse pensamento jurídico característico do positivismo científico, que afastava completamente qualquer contribuição das valorações filosóficas, psicológicas e sociológicas" (BITENCOURT, 2014, p. 262), razão pela qual optou-se por formalismos e pela exclusão de juízos valorativos quando de sua teorização (BITENCOURT, 2014, p. 263). Foi a partir dessa primeira grande sistematização que se propiciou o desenvolvimento em bases relativamente sólidas da teoria do delito (ESTEFAM e GONÇALVES, 2015, p. 277).

Não é por outro motivo que se considera o sistema causalista clássico como precursor do direito penal estruturado¹.

Pois bem. Para o causalismo clássico, a formulação de crime se vê ancorada na ação humana naturalística (movimento corpóreo que promove uma alteração no mundo exterior) e no resultado criminoso, ambos ligados por um nexo de causalidade (BITENCOURT, 2014, p. 262), ressaltando que ao direito penal apenas interessam atos proibidos pelo direito, ou seja: antijurídicos (OLIVÉ et al, 2011, p. 222).

Além disso, após essa análise de tipicidade, deve-se perquirir o elemento psíquico do agente. Neste modelo de base causalista, portanto, a culpabilidade é representada, exclusivamente pelos aspectos subjetivos - dolo e culpa (TAVARES, 2018, p. 54) -, razão pela qual convencionou-se dizer que a culpabilidade para o causalismo clássico é apenas psicológica (BITENCOURT, 2014, p. 441-443). Nesse modelo, a imputabilidade é mero pressuposto da culpabilidade (BITENCOURT, 2014, p. 442).

Não é por outro motivo que a culpabilidade no sistema causalista clássico é definida como "um nexo psicológico entre o sujeito e o resultado do crime" (OLIVÉ et al., 2011, p. 437).

\footnotetext{
${ }^{1}$ Nas palavras de Karl Engisch (apud OLIVÉ et al., 2011, p. 224): "foi Lizst quem, como o grande arquiteto da sistemática do direito penal atualmente dominante, elaborou deste modo um sistema categorial. Para isso, teve muito presente precisamente como genus proximun um conceito do delito (isto é, do injusto culpável) comum ao direito civil e ao direito penal, do qual se desenvolveu - conceito específico de delito ressaltando as características do delito punível, cujas características de punibilidade qualificou posteriormente Beling como características do tipo."
} 
Toda essa estrutura permite destrinchar o fato criminoso em dois grandes aspectos: o objetivo - composto pela tipicidade e antijuridicidade - e o subjetivo - composto pela culpabilidade (BITENCOURT, p. 262).

Dessa forma, o que se observa é uma estrutura da teoria do delito voltada para, primeiramente, analisar todos os elementos objetivos (tipicidade e antijuridicidade) do fato criminoso. Após, realizando um juízo positivo, passa-se à análise dos elementos estritamente subjetivos (culpabilidade, composta exclusivamente pelo dolo e pela culpa).

Portanto, o dolo e a culpa em tal sistema confundem-se com a própria culpabilidade, eis que esta é composta integral e exclusivamente por aqueles.

\subsection{O sistema causalista neoclássico (neokantismo)}

Como o próprio nome indica, o sistema neoclássico, também conhecido como neokantismo, é inspirado na filosofia valorativa de Immanuel Kant e teve como expoentes Edmund Mezger e Reinhard Frank (NUCCI, 2019, capítulo XIV, item 2.2; ROXIN, 1997, p. 200).

A principal "evolução" proporcionada pelo causalismo neoclássico em relação ao causalismo clássico foram os incrementos valorativos inseridos na teoria do crime. Desse modo, incluem-se elementos valorativos em todos os caracteres do crime.

Como esclarecem Ferré Olivé, Miguel Paz, William Terra e Alexis Couto de Brito (2011, p. 225), passou-se a compreender a ação não só como uma simples modificação do mundo exterior (aspecto meramente objetivo), como também a negação da ação esperada. Tal acréscimo possibilitou uma melhor compreensão dos delitos omissivos. Quanto à tipicidade, o causalismo neoclássico passou a admitir - ainda que como exceção - a possibilidade de inserção de aspectos subjetivos, tais como o animus injuriandi ou o animus lucrandi nos crimes patrimoniais. Já quanto à antijuridicidade, embrionariamente, ganhou relevo a discussão acerca do bem jurídico tutelado e sua necessária violação para a concretização do crime. 
Contudo, em nossa ótica, foi a culpabilidade que sofreu o incremento mais significativo, eis que passou a comportar não mais um viés única e exclusivamente subjetivo - tal como acontecia no causalismo clássico -, mas sim um viés psicológico-normativo (ESTEFAM e GONÇALVES, 2015, p. 282-284).

Para o causalismo neoclássico, o conteúdo da culpabilidade não pode ser integralmente subjetivo (culpa e dolo), tal como é para o causalismo clássico. Deve, assim, revelar também um juízo de valor em relação ao autor do fato típico e ilícito².

Portanto, incrementou-se o conceito de culpabilidade, acrescendo-se o aspecto normativo, isso porque (a) erigiu-se a imputabilidade como elemento da culpabilidade (e não mais como mero pressuposto); (b) incrementou-se o dolo com o elemento da consciência da ilicitude (aproximação do chamado dolus malus) ${ }^{3}$; e (c) incluiu-se a exigibilidade de outra conduta.

Assim, no tocante específico ao dolo e à culpa, o causalismo neoclássico, por incorporar elementos normativos na estrutura da culpabilidade, foi capaz de

\footnotetext{
2 Nas palavras de FRANK (apud OLIVÉ et al, 2011, p. 225): "Para que se possa reprovar alguém por seu comportamento, há um triplo pressuposto: 1․ Uma aptidão espiritual normal do autor, ao que nós denominamos imputabilidade. Se ela existe em alguma pessoa, então está dito que seu comportamento antijurídico pode ser convertido, em geral, em reprovação, mas, todavia, não se pode afirmar que the corresponda uma reprovação no caso particular. Para isso necessita-se, ademais: $2^{\circ}$. Uma determinada relação concreta psíquica do autor com o fato em questão ou a possibilidade desta, conforme o qual aquele discerne seus alcances (dolo) ou bem os poderia discernir (culpa). Na existência destas exigências, a reprovação não estaria fundamentada. Para isso é necessário que, ademais, concorra: $3^{\circ}$. A normalidade das circunstâncias sob as quais 0 autor atua. Quando uma pessoa imputável realiza algo antijurídico, consciente ou podendo estar consciente das consequências que traz paralelamente ao seu agir, pode ser sujeito, em geral, de uma reprovação, segundo a interpretação do legislador. Mas o que é possível em geral, em um caso particular pode ser impossível; assim, não cabe reprovabilidade quando as circunstâncias concomitantes tenham sido um perigo para o autor ou para uma terceira pessoa e a ação proibida executada os poderia salvar."

$3 \mathrm{Em}$ sentido muito próximo ao aqui defendido, confira-se as palavras de ESTEFAM e GONÇALVES (2015, p. 285): "no sistema clássico, não se dava solução satisfatória para tal situação. Com o escopo de dar uma resposta a esse problema, alguns autores integrantes do sistema neoclássico 'ressuscitaram' a teoria do dolus malus e, com uma roupagem atualizada para a época, criaram o chamado 'dolo híbrido ou normativo', acima mencionado. Segundo esta concepção de dolo, não bastam a consciência da conduta e a vontade de realizar o ato, exigese, para tais fins, que o agente tenha consciência da ilicitude do comportamento. Assim, aquele que age sem ter consciência da ilicitude de sua conduta mão atua dolosamente. No exemplo acima proposto, o sujeito seria absolvido por falta de dolo. Tal solução, todavia, não ficou isenta de questionamentos."
} 
chegar ao "dolo normativo", bem como melhor conseguiu realizar um tratamento legal da culpa, que, essencialmente, é normativa.

\subsection{O sistema finalista}

O sistema finalista foi idealizado por Hans Welzel (2001) e tem como principal ${ }^{4}$ elemento distintivo em relação ao causalismo a própria noção de ação. Welzel deixou de lado a ação como sendo algo natural e elementar, movimento corpóreo que promove uma alteração no mundo exterior - conceito este característico do causalismo - para defini-la com base no acontecimento final ${ }^{5}$.

Foi também o finalismo de Welzel que foi capaz de trazer uma concepção puramente normativa da culpabilidade - o que de certa forma já havia sido iniciado no causalismo neoclássico, que adota uma concepção psicológicanormativa da culpabilidade - ao trazer o dolo e a culpa como elemento da tipicidade, e não mais da culpabilidade (BITENCOURT, 2014, p. 268). Dessa forma, a tipicidade passou a contar com o elemento subjetivo (dolo e culpa) em sua estrutura.

\footnotetext{
${ }^{4}$ Neste sentido, Victor Leal Nunes (apud NUCCI, 2019, capítulo XIV, item 1.3): "Tal como o causalismo, o finalismo vê no delito, analiticamente, uma ação típica, antijurídica e culpável. Mas, como este sistema advém de uma concepção finalista da conduta, é na teoria da ação que se situa a diferença entre os dois sistemas".

Da mesma forma, Roxin (1997, p. 199): "Su ponto de partida es una concepto de acción distinto del de las anteriores concepciones sistemáticas y muchos más rico em contenido. Para esta teoría la 'esencia' de la acción, que determina toda la estrutura sistemática, estriba en que, mediante su anticipación mental y la correspondiente selección de medios, el hombre controla el curso causal dirigiéndolo hacia hacia un determinado objetivo, es decir, lo 'supradetermina de modo final'".

5 "A ação humana é exercício de uma atividade final. A ação é, portanto, um acontecimento final e não puramente causal. A finalidade, o caráter final da ação, baseia-se no fato de que o homem, graças ao seu saber causal, pode prever, dentro de certos limites, as possíveis consequências de sua conduta, designar-lhe fins diversos e dirigir sua atividade, conforme um plano, à consecução desses fins. Graças ao seu saber causal prévio, pode dirigir seus diversos atos de modo que oriente o suceder causal externo a um fim e o domine finalisticamente. A atividade final é uma atividade dirigida conscientemente em razão de um fim, mas é a resultante causal da constelação de causas existentes em cada momento. A finalidade é, por isso - dito de forma gráfica - "vidente", e a causalidade, 'cega'."(WELZEL, 2001, p. 27).
} 
Essa migração do elemento psicológico para o tipo penal trouxe consequências para a interpretação do dolo: se de um lado, o causalismo neoclássico enxerga o dolus malus (em razão de acrescer a consciência da antijuridicidade em seu conteúdo); por outro lado, o finalismo trouxe apenas o "dolo natural" para a tipicidade, ou seja, manteve o elemento da consciência (agora, potencial) da antijuridicidade na culpabilidade (OLIVÉ et al., 2011, p. $227)^{6}$.

Portanto, no tocante específico ao dolo e à culpa, o finalismo migrou-os para a tipicidade.

Desse modo, o dolo passou a ser enxergado a partir do binômio vontade e consciência, classificando-o como natural. Já no tocante aos crimes culposos, asseverou-se que o conceito de ação finalística para tais crimes deveriam ser interpretado de modo a abarcá-los na teoria do delito. ${ }^{7,8}$

\footnotetext{
${ }^{6}$ Em sentido semelhante, confira-se as lições de Guilherme Nucci (2019, capítulo XIX, item 1), parafraseando Nélson Hungria: "Na ótica finalista, o dolo é a vontade consciente de praticar a conduta típica (denomina-se dolo natural). Na doutrina clássica, de visão causalista, o dolo é a vontade consciente de praticar a conduta típica, acompanhada da consciência de que se realiza um ato ilícito (denomina-se dolo normativo). Nas palavras de HUNGRIA: 'O nosso direito penal positivo concebe o dolo como intenção criminosa. É o mesmo conceito do dolus malus do direito romano, do böser Vorsatz do Código Penal austríaco, ou da malice da lei inglesa"'.

Também preciosas são as palavras de Juarez Tavares (2020, p. 273): "O dolo costuma ser definido como a 'consciência e vontade de realizar os elementos objetivos do tipo'. Essa definição adveio do finalismo e, praticamente, se projetou até os dias atuais".

7 "O princípio do qual derivam os delitos culposos pode ser formulado, do modo mais conciso e correto, pelo adágio latino: Quidiquid agis, prudenter agas et respice finem (em que a palavra finis não se refere ao fim perseguido pelo agente, mas ao final ou ao desenlace). Os delitos culposos baseiam-se também na consideração da ação humana como uma obra: a vontade, que, partindo do fim, seleciona os meios da ação, necessários para a sua consecução, deve atender na seleção e utilização dos meios às consequências que estes possam produzir, juntamente com o fim ou em seu lugar. Nesse ponto intervém o ordenamento jurídico, e ordena que, na realização de toda ação que possa ter consequência. O conteúdo decisivo do injusto dos delitos culposos consiste, por isso, na divergência entre a ação realmente empreendida e a que deveria ter sido realizada em virtude do cuidado necessário no tráfego. Consiste, sobretudo, no desvalor da ação, enquanto o desvalor do resultado produzido (a lesão ou o perigo de lesão a um bem jurídico) tem apenas uma significação restritiva, delimitadora, ao destacar, entre as condutas que não correspondem ao cuidado devido, aquelas que têm relevância para o Direito Penal" (WELZEL, 2001, p. 76-77).

8 "(...) mesmo no crime culposo há intenção na conduta do agente. Ocorre que a finalidade não é a de produzir o resultado. Assim, por exemplo, se um motorista conduz seu veículo em alta velocidade e perde o controle do automóvel, atropelando alguém por imprudência, existiu intenção no comportamento (chegar mais cedo no destino, acelerar o carro para verificar sua potência, etc.)" (ESTEFAM e GONÇALVES, 2015, p. 291).
} 


\subsection{O sistema funcionalista}

O sistema funcionalista é dividido ${ }^{9}$ em duas correntes: teleológica e sistêmica. Seus expoentes, respectivamente, são Claus Roxin e Günther Jakobs.

Inicialmente, vamos dar enfoque especial ao pensamento funcional teleológico.

Se as "evoluções" proporcionadas pelo sistema finalista em relação ao causalismo se deram, principalmente, nos âmbitos do conceito de ação e na migração absoluta do elemento subjetivo (dolo e culpa) para a tipicidade, o sistema funcional teleológico ocupou-se de fazer uma reestruturação da teoria do delito através do diálogo com a política criminal ${ }^{10}$. Por isso, todas as categorias (ação, tipicidade, antijuridicidade e responsabilidade) do sistema funcional teleológico possuem traços dotados de caracteres de política criminal, com olhos para a tutela do bem jurídico (OLIVÉ et al., 2011, p. 228; BITENCOURT, 2014, p. 270) ${ }^{11}$.

Assim sendo, o que se vê é que o sistema funcional teleológico tem certas categorias alteradas. Por exemplo, desenvolveu a teoria da imputação objetiva,

\footnotetext{
9 "A teoria funcionalista, iniciada por Claus Roxin, na Alemanha, sob a perspectiva teleológica, e depois continuada por Günther Jakobs, sob outro ambiente, denominado sistêmico, teve por finalidade sepultar o finalismo e seus critérios ontológicos, transferindo-se para a teoria do crime elementos puramente normativos. O funcionalismo não teve - nem tem - por finalidade quebrar a estrutura conceitual analítica do delito, que continua a ser um fato típico, antijurídico e culpável, mas pretende fornecer novos conceitos a cada uma dessas categorias, a ponto de funcionalizar a estrutura do delito, aprimorando-a para servir à legitimação da pena, sempre na perspectiva da política criminal (Roxin) ou de um sistema de normas (Jakobs). No cenário do funcionalismo, encontra, ainda, a teoria da imputação objetiva, a ser analisada no capítulo referente ao nexo causal." (NUCCl, 2019, capítulo XIX, item 2.5)

10 "Numa síntese: o finalista pensa que a realidade é unívoca (primeiro engano), e que basta conhecê-la para resolver os problemas jurídicos (segundo engano - falácia naturalista); o funcionalista admite serem várias as interpretações possíveis da realidade, de modo que 0 problema jurídico só pode ser resolvido através de considerações axiológicas - isto é, que digam respeito à eficácia e à legitimidade da atuação do direito penal" (GRECO, 2000).

11 Nas palavras do próprio ROXIN (1997, p. 203): "Aproximadamente desde 1970 se han efectuado intentos muy discutidos de desarrollar un sistema 'racional-final (o teleológico)' o 'funcional' de Derecho penal. Los defensores de esta orientación están de acuerdo - con muchas diferencias em lo demás - en rechazar el punto de partida del sistema finalista y parten de la hipótesis de que la formación del sistema jurídico-penal no puede vincurlarse a realidades ontológicas previas (acción, causalidad, estructuras lógico-reales, etc.), sino que única y exclusivamente puede guiarse por las finalidades del Derecho penal."
} 
cuja premissa orbita o princípio do risco (ROXIN, 1997, 204; OLIVÉ et al, 2011, p. 229); a ampliação da categoria da culpabilidade para a de responsabilidade (ROXIN, 1997, p. 204) e o conceito de ação passa a ser entendido como "manifestação da personalidade" (NUCCI, 2019, capítulo XIV, item 2.5.1).

Já o funcionalismo sistêmico parte das ideias de Günther Jakobs, que por sua vez orienta-se nas ideias de Niklas Luhmann (OLIVÉ et al., 2011, 229). Se o funcionalismo teleológico construiu sua teoria do delito a partir de aspectos de política criminal, objetivando a tutela de bens jurídicos, o funcionalismo sistêmico parte da premissa de que são os fins da pena que devem nortear o sistema (BITENCOURT, 2014, p. 270).

Aliás, para Jakobs, a pena é a negação da negação. Isto é, se o crime estabelece uma conduta proibida (negação) e o sujeito incide em tal tipo penal, a pena tem que servir para censurar (negar) a conduta contrária a norma (negação) do sujeito que a praticou. É dentro dessa ótica que Jakobs funda seu sistema pautado exclusivamente na tutela da norma pela norma, a qual, em sua ótica, é capaz de manter a sociedade coesa e ordenada.

É nessa linha de encadeamento de ideias que Jakobs desenvolve uma teoria do tipo unitário, capaz de abranger crimes comissivos e omissivos, de modo que a posição de garante é exigível não só para os delitos omissivos, como também para os crimes comissivos (OLIVÉ et al, 2011, p. 231).

\section{Aproximações e distinções entre o dolo e a culpa nos sistemas causalista, finalista e funcionalista: uma análise do dolo eventual e da culpa consciente}

No item anterior, explanaram-se brevemente as principais distinções entre as teorias causalistas, finalista e funcional. Essas linhas gerais distintivas entre tais sistemas são necessárias para fornecer um substrato teórico mínimo para que se faça uma discussão adequada acerca das distinções entre dolo e culpa, especialmente o dolo eventual e a culpa consciente. 
Pois bem. Como já adiantado, no sistema causalista, o dolo e a culpa eram alocados na culpabilidade. No caso do sistema causalista neoclássico, rememora-se que houve a inclusão de elementos normativos.

Neste sentido, é imperioso destacar que, diante da opção por uma culpabilidade estritamente psicológica (causalismo clássico), restou inviável a realização de uma conceituação de culpabilidade capaz de abranger as formas dolosas e a culposas, notadamente a culpa inconsciente. Tal dificuldade se dava, exatamente, porque a culpa é um elemento normativo per se, o que inviabilizaria sob esta ótica um conceito de culpabilidade ancorado apenas e tão somente em uma culpabilidade psicológica (BITENCOURT, 2014, p. 443).

Dessa forma, o tratamento dos crimes culposos na teoria causalista clássica era tormentosa e foi sensivelmente melhor abordada no causalismo neoclássico, dada sua introjeção de elementos normativos não só na culpabilidade, como também nos elementos subjetivos. Daí porque fala-se em "dolo normativo" ou "dolo híbrido".

Ainda que haja essa distinção relevante acerca do elemento subjetivo para o causalismo clássico e neoclássico, é importante observar que, no tocante ao conteúdo específico do dolo, vê-se uma aproximação muito forte entre ambos, isso porque tais teorias apoiam-se, originariamente, na teoria da representação. Nas palavras de Bitencourt (2014, p. 357): "Segundo a teoria da representação, cujos principais defensores, em sua fase inicial, foram Von Liszt e Frank, para a existência do dolo é suficiente a representação subjetiva ou a previsão do resultado como certo ou provável".

Contudo, vê-se que tal teoria está em franco desuso. Aliás, os seus principais defensores (Von Listz e Frank) parecem ter adotado a teoria da vontade ou consentimento posteriormente, até mesmo para melhor explicar a tênue diferença entre o dolo eventual e a culpa consciente (BITENCOURT, 2014, p. 357-358), tendo em vista que o traço marcante da teoria da representação é 
a não distinção entre dolo eventual e culpa consciente (ESTEFAM e GONÇALVES, 2015, p. 315-316) ${ }^{12}$.

Em outras palavras: no causalismo, operou-se uma evolução interna dentro do próprio conteúdo subjetivo, especialmente no tocante à teoria neoclássica, a fim de aprimorar as explicações acerca da distinção entre dolo eventual e culpa consciente. Foi o que se observou com a formulação da chamada "fórmula de Frank" 13.

A culpa, por sua vez, para o sistema causalista, apresenta-se "tanto como a 'não previsão do resultado previsível', quanto também como a 'falta de precaução' ou o 'desprezo do cuidado requerido pela ordem jurídica e exigido pelo estado das circunstâncias"” (TAVARES, 2018, p. 56).

Neste sentido, a lógica causal é no sentido de que o elemento subjetivo é de gradação, o que significa dizer que a culpa é uma espécie de elemento subsidiário ao dolo, especialmente porque os critérios da culpa seriam analisados apenas se constatada a inexistência de dolo, de modo que o crime culposo, no causalismo, teria a mesma estrutura do delito doloso (TAVARES, 2018, p. 63; ROXIN, 1997, p. 997).

Não é por outro motivo que Juarez Tavares (2018, p. 54) é assertivo na afirmação de que a "negligência constitui neste sistema [causal] uma forma menor de culpabilidade e, por isso, menos importante, em que a responsabilidade deriva tão-somente de uma relação psicológica superficial, representada, segundo a tese da responsabilidade subjetiva, pela previsibilidade do evento".

\footnotetext{
12 Neste sentido, vale rememorar que há "duas fórmulas práticas, ofertadas por FRANK, que seriam elementos de uma possível definição dogmática. De acordo com a primeira fórmula, o dolo eventual seria evidenciado quando, diante das circunstâncias, supondo-se a ocorrência do resultado como certo, tal fato não implicaria um contra estímulo à conduta do agente (teoria hipotética do conhecimento). Pela segunda fórmula, haveria dolo eventual se o agente dissesse a si mesmo: 'não me importa o que acontecer, de qualquer forma atuo' (teoria positiva do consentimento)" (TAVARES, 2020, p. 315)

13 Hans Frank criou a chamada fórmula de Frank (teoria positiva do consentimento e teoria hipotética do conhecimento, 1908) - há dolo eventual quando o agente diz para si mesmo: "seja como for, dê no que der, em qualquer hipótese não deixo de agir" ou "aconteça o que acontecer, continuo a agir" (revela a indiferença do agente em relação ao resultado). Existe culpa consciente quando: "se acontecer tal resultado, deixo de agir". (PRADO, 2019, capítulo XXVI, item 6.4)
} 
Quanto ao finalismo, como já dito, uma das maiores revoluções realizadas se comparada à teoria causal se deu em razão da migração do elemento subjetivo (dolo e culpa) para o tipo penal, tornando a culpabilidade estritamente normativa.

Diante de tal tomada de postura, é possível observar que o elemento subjetivo doloso no finalismo é composto, apenas, da consciência e vontade, razão pela qual se diz que o dolo é "natural” (NUCCI, 2019, capítulo XIX, item 1).

Desta forma, o que diferencia o dolo no causalismo e o dolo no finalismo é, essencialmente, a sua alocação (culpabilidade no causalismo; e tipicidade no finalismo), assim como a sua própria estrutura, eis que o dolo no causalismo é híbrido, enquanto que no finalismo é natural. De outra parte, pode-se dizer que ambos são ontologistas, de modo que esta talvez seja a característica que mais os aproxime (BRANCO, 2014, p. 205) ${ }^{14}$.

Outra consequência relevante do finalismo que merece destaque, para os fins a que se destina este estudo, é a contribuição relevantíssima em termos de dogmática no tocante ao desvalor da conduta (injusto pessoal), que é erigido ao patamar de elemento constitutivo do injusto penal (BITENCOURT, 2014, p. 268; ROXIN, 1997, p. 997). Em nossa ótica, a relevância do desvalor da conduta é a pedra de toque para a compreensão dos delitos culposos, especialmente porque é este elemento que traz o conteúdo decisivo do injusto culposo, sendo que o

14 "Estão o causalismo como o finalismo, sublinha Busato, amparados numa concepção ontologicista de dolo, considerando-o um dado real e eminentemente psicológico que compete ao jurista identificar. Sendo o dolo um processo psicológico, em geral não há como se afirmar categoricamente quando o sujeito terá ou não conhecimento sobre o risco de produção do resultado. Desse modo, ainda que o indivíduo inadvertidamente acreditando na sorte não tenha pensado na lesão que advém, como poderia ocorrer no jogo da "roleta russa", não poderá ele ser isento de responsabilidade, cabendo reagir como se o elemento intelectual do dolo tivesse concorrido." (BRANCO, 2014, p. 205) 
desvalor do resultado tem como característica a delimitação das condutas que têm ou não relevância na seara penal (WELZEL, 2001, p. 76-77) ${ }^{15},{ }^{16}$.

No tocante específico à distinção entre dolo eventual e culpa consciente, é importante destacar que os finalistas, em regra, adotam a teoria da vontade, o que por si só já conduz à assertiva de diferenciação entre dolo eventual e culpa consciente. Contudo, como esclarecido acima, o próprio causalismo neoclássico, especialmente pelas mãos de Frank ${ }^{17}$, já passou a adotar a teoria da vontade para melhor realizar o tratamento dos casos de dolo eventual e culpa consciente. Aliás, o que se observa é que a maioria dos finalistas parecem, efetivamente, adotar a "fórmula de Frank" ou conceituações e distinções no tocante ao dolo eventual e a culpa consciente próprias de causalistas brasileiros - tais como Nélson Hungria e Aníbal Bruno - para distinguir o dolo eventual da

\footnotetext{
${ }^{15}$ Apenas a título de esclarecimento, é importante observar que embora WELZEl faça uma diferenciação entre o injusto doloso e culposo, há críticas no sentido de que sua abordagem finalista acaba por criar uma falha de tratamento nos crimes culposos. Neste sentido, confira-se as críticas de Ferré Olivé, Miguel Paz, William Terra e Alexis Couto de Brito (2011, p. 228), parafraseando Rodríguez Mourullo: "Um ponto fraco na abordagem finalista encontra-se nos crimes culposo, pois justamente nestes não se nota uma ação dirigida a um fim, mas o contrário: não há uma condução da ação para o resultado final. Tudo isso levou a uma profunda discussão sobre o conceito omn.

icompreensivo da ação. Como sustenta Rodríguez Mourullo, 'o defeito primordial dos finalistas é a pretensão de atribuir ao seu conceito de injusto validez universal, porquanto derivado da 'vinculante' estrutura lógico-objetiva da ação, tanto que a concepção do injusto depende da concepção mesma da norma jurídica, e afinal do direito, tenha acolhido e professe um determinado ordenamento jurídico. Não estamos, pois diante de um problema de 'natureza das coisas, senão diante de uma questão muito mais modesta de 'interpretação do Direito positivo'"'. ${ }^{16}$ É, aliás, em sentido muito próximo a esse que Juarez Tavares $(2018$, p. 72$)$ afirma que "aqui vigora, antes de tudo, o princípio de que o direito penal não se preocupa unicamente com 0 resultado lesivo a bens jurídicos, mas, principalmente, com ações realizadas de modo contrário às proibições jurídicas, destinada à proteção desses bens. Ressalta, assim, no conjunto de proibições, de modo primário, o desvalor da ação, como fundamento da especulação jurídicopenal. Contudo, ao direito penal o que importa, realmente, não é qualquer ação, mas somente a que possa configurar-se finalisticamente, ou seja, a que possa ser dirigida volitivamente no seu desdobramento causal. Nesse contexto, o direito penal proíbe, inicialmente, ações nas quais a vontade está dirigida à produção de resultado socialmente indesejável, quer se inclua no fim de agir, quer se constitua parte do meio empregado ou advenha como efeito secundário dessa ação, o que caracteriza, então, os delitos dolosos. Depois, proíbe as ações finais, não propriamente as com vistas à produção de resultados indesejáveis, mas aquelas em que o autor confia na nãoprodução desses resultados ou, até mesmo, nem haja pensado neles, do que decorre a formulação dos delitos culposos. Finalmente, numa proporção menor, determina-se a execução de ações para a manutenção de determinados bens jurídicos, o que dá lugar aos delitos omissivos".

${ }^{17}$ Nesse sentido, rememore-se a "fórmula de Frank".
} 
culpa consciente, como são os exemplos de Régis Prado (2019, capítulo XXVI, item 6.4) e Cezar Bitencourt (2014, p. 362-363) ${ }^{18}$.

Por fim, no funcionalismo ${ }^{19}$, observa-se uma divisão entre duas categoriais do delito: os de ação e os de infração de um dever (OLIVÉ et al, 2011, p. 229), sendo certo que os crimes culposos foram, inicialmente, tratados como delitos de infração de um dever e, apenas posteriormente, tratados em equiparação à estrutura dos crimes dolosos (ROXIN, 1997, p. 998; TAVARES, 2018, p. 199) 20 .

Portanto, deve-se frisar que, inicialmente, houve uma diferenciação sensível entre os injustos dolosos e culposos para o funcionalismo de Roxin, capaz de alterar a própria estrutura típica. Contudo, tal posição acabou por ser superada pelo próprio Roxin, em decorrência de sua evolução de pensamento.

Pois bem. Especificamente no conteúdo do dolo, não se observam grandes mudanças se comparadas as correntes do finalismo e do funcionalismo (NUCCI, 2019, capítulo XIX, item 1).

De modo geral, Roxin (1997, p. 415) divide as manifestações do dolo em: a intenção ou o propósito (dolo direto de primeiro grau); o dolo direto (dolo direto de segundo grau); e o dolo eventual ${ }^{21}$. Para Roxin (1997, p. 415), tal classificação

\footnotetext{
${ }^{18}$ Aqui, contudo, é importante abrir um parêntese para certas expressões de matizes causalistas que subsistem na parte geral do Código Penal e podem gerar confusões interpretativas. Refirome aos termos "sabe" e "deve saber", presentes, a título exemplificativo, nos artigos 130, 180, $\S 1^{\circ}$ e $316, \S 1^{\circ}$, todos do Código Penal. Sobre este particular sugerimos a seguinte leitura: BITENCOURT, Cezar Roberto. O "sabe" e o "deve saber" como moduladores da culpabilidade reflexões sobre inovações da Lei 9.426/96. In: Revista Brasileira de Ciências Criminais, v. 23, p. 31-40, jul./set. 1998.

19 Para melhor acomodar o presente artigo no espaço que lhe é destinado, optamos por tratar, apenas, do funcionalismo teleológico.

20 "La necesidad de tratar la conducta imprudente como problema del tipo resulta por tanto de transformaciones de la teoría del injusto (del recurso a la norma de determinación, del reconocimento del injusto personal y de la teoría de la imputación objetiva) que poseen validez para todo su ámbito y por tanto también para los delitos dolosos. Pero hay también argumentos específicos de la imprudencia para tal ubicación, pues está fuera de discusión que em amplios sectores el riesgo permitido marca el límite a partir de cuya superación comienza la imprudencia. Lo que está amparado por el riesgo permitido no es por tanto imprudente; pero lógicamente um riesgo permitido no puede estar sólo disculpado, sino que há de hacer que desaparezca ya el injusto" (ROXIN, 1997, p. 998).

21 "Comúnmente se distinguen tres formas distintas de dolo: la intención o propósito (dolus directus de primer grado), el dolo directo (dolus directus de segundo grado) y el dolo eventual (dolus eventualis). Las mismas se contraponen a las dos formas de la imprudencia, la consciente y la inconsciente. Resumiendo em forma de lemas: bajo el concepto de intención o propósito cae
} 
é importante porque, em tipos penais em que estejam presentes o que se denomina de especial fim de agir, há, de antemão, a possibilidade de excluir condutas que sejam praticadas mediante dolo eventual.

Quanto à culpa, Roxin adota, expressamente, a teoria da imputação objetiva como critério determinante para tais espécies de delitos. Em verdade, a base única para tratamento dos delitos culposos se dará através do critério da imputação objetiva, que se perfaz a partir da criação de um risco não autorizado ao bem jurídico tutelado (TAVARES, 2018, p. 199) ${ }^{22}$.

Contudo, o fato de ser a imputação objetiva o cerne do injusto culposo não significa dizer que Roxin retire totalmente o desvalor do resultado da estrutura típica. Em verdade, o desvalor do resultado é elemento fundante da teoria da imputação objetiva, e se dá em razão da concretização do risco no resultado (TAVARES, 2018, p. 202).

Dessa forma, a estrutura dos delitos culposos é calcada no desvalor do ato e da conduta, que se demonstra latente a partir da imputação objetiva ${ }^{23}$.

Embora sejam, de fato, as formulações de Frank e de Roxin muito próximas, há entre elas uma sutil diferença. De um lado, a fórmula de Frank tem viés prático, que visa colocar o terceiro intérprete no papel do autor dos fatos; de

lo que el sujeto persigue; por el dolo directo (de segundo grado) son abarcadas todas las consecuencias que, aunque no las persigue, el sujeto prevé que se producirán com seguridad; y com dolo eventual actúa quien no persigue um resultado y tampoco lo prevé como seguro, sino que sólo prevé que es posible que se producza, pero para el caso de su producción lo asume em su voluntad." (ROXIN, 1997, p. 415)

22 Neste sentido, tomamos a liberdade de transcrever uma breve passagem de Roxin (1997, p. 999) que bem sintetiza seu pensamento: "Es correcto el tipo de los delitos imprudentes, em la medida em que no contenga una descripción adicional de la conducta, se colma mediante la teoría de la imputación objetiva: un resultado que se imputa al tipo objetivo está causado imprudentemente, sin que se precise de ulteriores criterios. En realidad, tras la característica de la infracción del deber de cuidado se esconden distintos elementos de imputación que se caracterizan los presupuestos de la imprudencia de manera más precisa que tal cláusula general."

23 No tocante específico ao dolo eventual e à culpa consciente, ROXIN (1997, p. 427) as conceitua e as diferencia da seguinte maneira: "Con esta reserva se puede decir que hay que afirmar el dolo eventual cuando el sujeto cuenta seriamente con la posibilidad de la realización del tipo, pero a pesar de ello sigue actuando para alcanzar el fin perseguido, y se resigna así sea de buena o de mala gana - a la eventual realización de un delito, se conforma con ella. En cambio, actúa con imprudencia consciente quien advierte la posibilidad de producción del resultado, pero no se la toma en serio y en consecuencia tampoco se resigna a ella en caso necesario, sino que negligentemente confía en la no realización del tipo. Al respecto debe distinguirse entre la 'confianza' y una mera 'esperanza'". 
outro lado, a conceituação de Roxin coloca no centro da discussão os dados reais e empíricos disponíveis ao agente, levando-o em consideração como sujeito praticante do fato 24 .

Também, é possível traçar como critério diferenciador entre as formulações de Frank e de Roxin o grau de certeza do resultado adverso não pretendido. Se de um lado Frank exige que, para afirmar-se dolo eventual, é necessário que haja uma suposição da ocorrência do resultado como certo, ainda assim não implicando em um contraestimulo ao agente (TAVARES, 2020, p. 315), de outro lado Roxin contenta-se, para afirmar dolo eventual, em ter o sujeito levado em conta seriamente a possibilidade do resultado criminoso ${ }^{25}$. Trata-se, assim, de uma discussão de gradação da probabilidade e certeza do evento danoso.

Trata-se - é verdade - de distinção muito tênue, tendo em vista que o próprio Roxin (1997, p. 427) reconhece que é muitíssimo difícil a tarefa de reproduzir textualmente um fenômeno mental tão sutil consistente na diferenciação entre dolo eventual e culpa consciente, de modo que suas considerações são meras aproximações da realidade.

\footnotetext{
24 "Ao aplicar-se qualquer dessas fórmulas [de Frank] à definição de dolo eventual de Roxin, como decisão para a possível lesão de bem jurídico, ter-se-á, na verdade, uma sobreposição de juízos, a decisão do autor e a decisão do julgador sobre a decisão do autor, o que conduz a uma situação de juízos hipotéticos condicionais. Não será adequado afirmar que o dolo tem por base a decisão do autor no sentido da possível lesão de bem jurídico, quando essa afirmação decorre de uma decisão do julgador sobre a própria possibilidade. O raciocínio ficaria assim: o agente diz a si mesmo que a lesão é possível e se decide por ela. O julgador diz que a leão era possível e afirma que q decisão do agente foi nesse sentido. Como pode o julgador dizer que a decisão do agente foi nesse sentido? A conclusão do julgador só pode ser feita mediante a inclusão de um elemento condicional: se a decisão do agente for no sentido da possibilidade da lesão, haverá dolo eventual. A solução é inconclusiva. Como diz Hoyningen-Huene, nas proposições condicionais, quando a primeira afirmação não pode ser comprovada ou for indeterminada, 0 valor da veracidade de todo o raciocínio é indeterminada, o valor de veracidade de todo o raciocínio é indeterminado. Só será conclusiva, então, a decisão do julgador quanto á afirmação do dolo eventual, se tratar de ato de autoridade. Mas para isso não se precisa de qualquer demonstração, o que viola, evidentemente, a estrutura do Estado democrático de direito, o qual se sedimento na motivação adequada dos atos judiciais" (TAVARES, 2020, p. 315-316).

${ }^{25}$ Neste sentido, vale rememorar as críticas feitas por Roxin à "fórmula de Frank", citando como exemplo o caso da barraca de tiro de Lacmann. Veja-se: "Aquí es seguro que el sujeto no habría actuado em caso de conocimento seguro del fallo, pues em tal caso sólo habría conseguido de su disparo riesgos y no ganancias. No obstante, hay que apreciar dolo eventual: el sujeto había incluido el fracaso em los cálculos de su plan, porque las perspectivas de éxito tenían para él más valor que el riesgo de fallar" (ROXIN, 1997, p. 438).
} 


\section{CONCLUSÃO}

Este trabalho objetivou explicitar, em um primeiro momento, as distinções existentes entre a teoria do delito que parte de bases causalistas, finalistas e funcionalistas.

Em um segundo momento, buscou-se tratar da evolução havida entre os institutos do dolo e da culpa no âmbito das teorias causalista, finalista e funcionalista, com especial enfoque aos institutos da culpa consciente e do dolo eventual.

Como se pode notar, a teoria do delito sofre uma ruptura estrutural na passagem do causalismo para o finalismo, especialmente em razão do deslocamento do elemento subjetivo da culpabilidade - no causalismo - para a tipicidade - no finalismo. Essa ruptura estrutural não aconteceu se comparada à passagem do finalismo para o funcionalismo, especialmente porque o elemento subjetivo permaneceu alocado na tipicidade.

Em verdade, a maior ruptura que se deu entre o finalismo e o funcionalismo diz respeito ao giro teórico do funcionalismo, que parte da inserção de critérios de política criminal no âmago de sua construção, o que acaba por influenciar a teoria do delito formulada. De um lado, Roxin centra seus esforços na proteção de bens jurídicos (funcionalismo teleológico); e de outro lado, Jakobs orbita sua teoria a partir da necessidade de proteção da norma (funcionalismo sistêmico).

No tocante específico à diferenciação entre o dolo eventual e a culpa consciente, pode-se observar que o causalismo neoclássico - após uma evolução da teoria da representação para a teoria da vontade - e o finalismo tendem a colocar suas bases de diferenciação em patamares muitíssimos próximos, o que pode ser verificado pela utilização da "fórmula de Frank" por finalistas e, até mesmo, pela distinção a partir de ideias de autores classicamente causalistas, como é o caso de Aníbal Bruno e Nélson Hungria. 
Já quanto à distinção entre o dolo eventual e a culpa consciente na teoria funcionalista, sob a ótica de Roxin, pode-se notar uma alteração quase que imperceptível, tendo em vista que Roxin tece algumas críticas à "fórmula de Frank", buscando a conceituação do dolo eventual e da culpa consciente mais condizente com sistema de tutela aos bens jurídicos.

\section{REFERÊNCIAS}

BITENCOURT, Cezar Roberto. O "sabe" e o "deve saber" como moduladores da culpabilidade - reflexões sobre inovações da Lei 9.426/96. Revista Brasileira de Ciências Criminais, v. 23, p. 31-40, jul./set. 1998.

BITENCOURT, Cezar Roberto. Tratado de Direito Penal: parte geral. v. 1, 20. ed. São Paulo: Saraiva, 2014.

BRANCO, Bruno Cortez Torres Castelo. O dolo como realidade axiológica e a superação das teorias ontologicistas da ação. Revista Justiça e Sistema Criminal, v. 6, n. 10, p. 199-214, jan./jun. 2014.

ESTEFAM, André; GONÇALVES, Victor Eduardo Rios. Direito Penal Esquematizado: parte geral. 4. ed. São Paulo: Saraiva, 2015.

GRECO, Luis. Introdução à dogmática funcionalista do delito - em comemoração aos trinta anos de "política criminal e sistema jurídico penal" de Roxin. São Paulo. Revista Brasileira de Ciências Criminais, vol. 32, p. 120-163, out./dez., 2000.

NUCCI, Guilherme de Souza. Curso de Direito Penal: parte geral - arts. $1^{\circ}$ a 120 do Código Penal. 3. ed. Rio de Janeiro: Forense, 2019. v. 1

OLIVÉ, Juan Carlos Ferré et al. Direito Penal Brasileiro: parte geral - princípios fundamentais e sistema. São Paulo: Revista dos Tribunais, 2011.

PRADO, Luiz Regis. Curso de Direito Penal Brasileiro. 17. ed. Rio de Janeiro: Forense, 2019.

ROXIN, Claus. Derecho Penal Parte General: fundamentos. La estructura de la teoría de delito. Tradução de Diego-Manuel Luzón Peña, Miguel Díaz y Harcía Conlledo e Javier de Vicente Remesal. Madrid: Civitas, 1997.

TAVARES, Juarez. Fundamentos de teoria do delito. 2. ed. Florianópolis: Tirant lo blanch, 2020. 
TAVARES, Juarez. Teoria do crime culposo. 5. ed. Florianópolis: Tirant lo blanch, 2018.

WELZEL, Hans. O novo sistema jurídico-penal: uma introdução à doutrina da ação finalista. Tradução, prefácio e notas de Luiz Régis do Prado. São Paulo: Revista dos Tribunais, 2001. 